\title{
Acute Inhalation of Generator Exhaust-Fumes May Impair Learning and Memory in Mice
}

\author{
Musa Ibrahim Kurawa \\ Department of Human Physiology, \\ Faculty of Basic Medical Sciences, \\ College of Health Sciences, \\ Bayero University, Kano. \\ P.M.B. 3011, Kano. \\ Kano State, Nigeria.
}

Email: mikurawa2012@gmail.com

\begin{abstract}
The study assessed the effects of acute inhalation of generator exhaust fumes on the anxiety-associated learning and memory (LEM), and motor coordination in mice. Twenty-four mice were divided into 4 groups. First and second groups were tested for motor coordination (beam walk) and LEM (Elevated Plus Maze, EPM) respectively. Mice in the experimental groups were exposed to the generator fume for 30min., 1hr., and $2 \mathrm{hrs}$ respectively before the tests. In Day 1, experimental animals showed significant decrease in the mean TL $(13.4 \pm 1.5 \mathrm{sec}$.) and an increase $(73 \pm 8.4 \mathrm{sec}$.) at 30min. and $1 \mathrm{hr}$ respectively, when compared to their controls $(28.6 \pm 5.2 \mathrm{sec}$.$) and (21.8 \pm 4.4 \mathrm{sec}$.$) . In day 2$, there were significant increase in the mean TLs during the 30min. (48.4 $\pm 12.8 \mathrm{sec}$.) and $2 \mathrm{hrs}$ exposures $(66.8 \pm 15.3 \mathrm{sec}$.$) , when compared to their controls (13.6 \pm 1.9 \mathrm{sec}$.$) and (22.6 \pm 6.6 \mathrm{sec}$.$) respectively.$ The result suggests decreased ability of the exposed mice to learn and recall the new behaviour. There was significant increase in the mean \% COHb level of the experimental group $(2.06 \pm 0.012 \%)$ when compared to the control $(0.76 \pm 0.089 \%)$. Exposure to $\mathrm{CO}$ from the generator exhaust fumes impaired learning and memory in mice.
\end{abstract}

Keywords: Carbon monoxide, Learning and Memory, Motor coordination, Elevated Plus Maze, Beam walk.

\section{INTRODUCTION}

Human beings live together in harmony with other living and non-living things. These relationships help to establish a balanced ecosystem in agreement with nature. However due to population growth, industrialisation and other human activities, the environment became saturated with diverse pollutants giving rise to pollution. Significant sources of air pollution in urban areas of developing countries like Nigeria may include but are not limited to emissions from motor vehicles (Mayer, 1999) and generator exhaust (Stanley et al., 2010). Carbon monoxide is a major air pollutant both indoors (Ayodele, 2007) and outdoors (Ajayi and Dosunmo, 2002) because of increased use of biofuel as a major source of energy for cooking.

Gasoline and diesel fuels are mixtures of hydrocarbon compounds containing hydrogen and carbon atoms. In a "perfect" engine, oxygen $\left(\mathrm{O}_{2}\right)$ in the air would convert all the hydrogen 
and carbon in the fuel to water and carbon dioxide $\left(\mathrm{CO}_{2}\right)$ respectively. In reality, the combustion process is not "perfect" therefore $\mathrm{CO}$ is produced instead of $\mathrm{CO}_{2}$. Also, production of $\mathrm{CO}$ is subject to the engine maintenance and nature of the fuel used (United States Air and Radiation, 2011). Petrol produces 28 times more CO than diesel (Campbell, 2009).

Carbon monoxide (CO) is one of the most common and widely distributed air pollutants in the world. It is a colourless, odourless, and tasteless gas that is poorly soluble in $\mathrm{H}_{2} \mathrm{O}$ and has a slightly lower density than air (United States Air Quality Criteria, 2000). Although CO is not among the normal respiratory gases, its physio-chemical similarities with $\mathrm{O}_{2}$ allow it to be transported through the airways and across alveolo-capillary membranes in a similar way. Therefore, at rest, and without exogenous exposure, minute quantity $(0.4-0.7 \%)$ of $\mathrm{CO}$ in form of carboxy-haemoglobin $(\mathrm{COHb})$ is produced endogenously in the body from catabolism of Haemoglobin $(\mathrm{Hb})$ and acts as physiologic smooth muscle relaxant, neurotransmitter and cytoprotector against oxidative stress (Ryter et al., 2004; USEPA, 2011). However, high concentrations of $\mathrm{CO}$ due to exogenous exposure may result to avid attachment to $\mathrm{Hb}$ and impaired $\mathrm{O}_{2}$ delivery to organs especially the highly metabolic ones like the brain and heart.

Neurological symptoms are the most frequent in any case of $\mathrm{CO}$ poisoning. Early symptoms of mild poisoning may include headache, dizziness, weakness, nausea, confusion, disorientation, and visual disturbances, while severe exposures may result in confusion, loss of consciousness, or death (Amitai et al., 1998). Symptoms of chronic CO poisoning like chronic fatigue, affective conditions, emotional distress, memory deficits, and difficulty in walking are usually subtle and may be overlooked as part of daily life chores (Penney, 2008). This could be one of the many reasons why CO is considered "the silent killer". There could also be delayed manifestation of neuropsychiatric impairment days after poisoning has occurred (Lam et al., 2004).

Carbon monoxide poisoning was defined as any case of accidental or deliberate exposure with a history suggestive of $\mathrm{CO}$ exposure and exhibiting symptoms and signs of $\mathrm{CO}$ intoxication as well as elevated blood \% COHb levels. Carbon monoxide poisoning accounts for 50,000 emergency department visits per year in the U.S. and is the most common cause of death due to poisoning in the country (Hampson et al., 1996). Even with the paucity of data (Ajayi, A. and Dosunmu, 2002) high amounts of $\mathrm{CO}$ were recorded in some cities in Nigeria. Ambient levels in Ibadan city alone were between 3 and 55 ppm (Sunny et al., 2008). The average indoor $\mathrm{CO}$ values measured in Kano were between $4.93 \mu / \mathrm{m}^{3}$ in the municipality and $5.49 \mu / \mathrm{m}^{3}$ in Sabon Gari area of the state (Ayodele et al., 2007). The above values are by far beyond the U.S. National Ambient Air Quality Standards (U.S. NAAQS, 2011).

There was paucity of reported data on the incidence of acute or that of chronic toxicity in Nigeria. The few suspected cases of acute CO poisoning brought to the hospitals were grossly underestimated (Augustine, 2002). This is because the symptoms of CO poisoning are general symptoms (Samuel et al., 2007) and mimic that of other common illnesses like flu (U.S. NAAQS, 2011). The U.S. Consumer Product Safety Commission (CPSC) of 2002 stated that every house should have a $\mathrm{CO}$ alarm and every major road junction must have one $\mathrm{CO}$ monitoring station to monitor $\mathrm{CO}$ levels; however, this is not found in Nigeria. Some hospitals in Nigeria are poorly equipped with CO-oximeter to make diagnosis easier. Therefore, poisonings are grossly under-reported or frequently misdiagnosed as usual flu symptoms. 
There is a global transition to cleaner sources of energy and less environmental pollution. However, in Nigeria there is still increased importation of gasoline-powered generators due to instability of the main power grid (Akinbami et al., 2001). The use of portable generators in the U.S. and other developed countries is only circumstantial, during power outages caused by winter storms or during forest camping (Niel et al., 2005); but in Nigeria it is the usual source of power.

Similar studies were lacking after searching the literature because most CO poisonings occur accidentally during fire out brakes or use of generators in poorly ventilated houses when the exhaust seeps into rooms where people sleep. Severe cases of CO toxicity led to death, however, mild to moderately cases present with clinical features similar to that of common flu. Because autopsies are not usually conducted to ascertain the cause of death, therefore most cases were not reported, but end up as mainstream news from media houses. The aim of the study was therefore to assess the effects of acute, mild, $\mathrm{CO}$ poisoning from generator exhaust fumes, that may not kill but can affect the functions of vital organs such as the brain in mice, since the research cannot be replicated on human subjects.

\section{MATERIALS AND METHODS}

\section{Materials}

Source of carbon monoxide: Gasoline powered generator (TIGER, TG950, 220v/240v) manufactured by Suzhou Tiger Power Machine Co., Ltd., China served as the source of CO.

Portable digital carbon monoxide gas analyser: The CO meter, Amprobe, CM100 was placed inside the gas chamber to record the dose of $\mathrm{CO}$ in parts per million (ppm). The dose of 100-150 ppm of CO exposure was maintained throughout the study by adjusting the positions and the direction of the exhaust fumes of the Generator depending on the wind direction.

Gas chamber: The gas chamber measures $150 \times 100 \times 100 \mathrm{~cm}$ (length $\times$ breadth $\times$ height). There was an open window measuring $30 \times 40 \mathrm{~cm}$ that allows the fumes into the chamber and also partial ventilation to fresh air.

\section{Methods}

Animals: Twenty-four adult swiss albino mice weighing between 18-32 g were used for the study. Mice were maintained at room temperature, fed on standard feed, and allowed access to tap water ad libitum. They were allowed to acclimatize with the environment for at least two weeks before commencement of the study.

Grouping: Mice were randomly assigned into one of the four groups. The first group was tested for motor coordination using beam walk paradigm and the second group for learning and memory, using Elevated Plus Maze (EPM) paradigm. The $3^{\text {rd }}$ and $4^{\text {th }}$ groups were their controls. Female mice were tested without monitoring the oestrous cycle.

Exposure of mice to $\mathrm{CO}$ from the generator exhaust fumes: Animal cages of the experimental groups were placed inside the gas chamber. Mice in the experimental groups were directly exposed to the exhaust fumes of the generator through the window for 30 minutes, 1 hour and 2-hour periods respectively before the neurobehavioral tests. The exposure method was adopted from a study by Samuel and Micha, (2007) where human subjects were accidentally exposed to fumes of gasoline-powered generator $(5 \mathrm{~kW}, 3000$ $\mathrm{U} / \mathrm{min}$.) directly adjacent to a long stable where they were sleeping. The two control groups were however maintained on fresh room air. 


\section{Neurobehavioral Tests:}

Assessment of motor coordination using the beam walk test: In the beam-walk test, mice were trained to traverse an elevated, narrow ruler beam (for training) or a round beam (for the test) to reach an enclosed escape goal box in a model described by Stanley, (2005). The latency and foot-slip measurements were taken as the mouse traversed the beam.

Assessment of learning and memory using the elevated plus maze test: For learning and memory, the EPM paradigm as described by Itoh et al., (1990) was used. On the first day (D1/ acquisition test) a mouse was placed at the end of one of the open arms, facing away from the central platform. Latency for the mouse to enter one of the closed arms was recorded in seconds. Following entry into an arm, the mouse was allowed to explore the apparatus for 30 seconds. Twenty-four hours later, the second trial (retention/ recall test) was performed. The time taken for a mouse to move from the starting point of the open arm to any of the closed arms was measured (in seconds) to indicate learning (D1) and memory (D2) (Itoh et al., 1990).

Determination of the blood carboxyhaemoglobin in mice: At the end of the neurobehavioral tests (which took 3 days), mice were sacrificed, and blood samples were collected in an EDTA bottles via cardiac puncture. The blood samples were later processed and used for estimation of the \% $\mathrm{COHb}$ by means of spectrophotometric method (Ernest and Carol, 1984).

Data analysis: Data obtained from the study were expressed as means \pm SEM. Student's ttest was used to compare the means between experimental and control groups, as well as between Day-1 and Day-2 of the groups. For all evaluations, values of $\mathrm{p}<0.05$ were considered to imply statistical significance. Microsoft Office Excel version 2007 and SPSS version 15.0 were employed in analysing the data.

\section{RESULTS}

Learning: When transfer latencies (TL) of the control and experimental groups were compared in the three exposure periods, only the 30 minutes and 1-hour exposures showed significant change with $\mathrm{P}$ values of 0.023 and 0.001 respectively, at $\mathrm{P}<0.05$. Although latency of the experimental group drops to $13.4 \pm 1.5$ seconds during the 30 minutes of $\mathrm{CO}$ exposure, that of 1 hour exposure period increased to $73 \pm 8.3$ seconds when compared to their respective controls ( $28.6 \pm 5.2 \mathrm{sec}$.) and $(21.8 \pm 4.4 \mathrm{sec}$.) as observed in Figure 1 .

Memory: There were significant increases in the TLs of the experimental group during the 30 minutes $(48.2 \pm 12.8$ sec.) and 2 hours $(66.8 \pm 15.3 \mathrm{sec}$.) of exposure as compared to the controls (13.6 $\pm 1.9 \mathrm{sec}$.) and (22.6 $\pm 6.6 \mathrm{sec}$.), respectively (Fig. 2$)$.

Motor coordination: There were no statistically significant differences between the control and experimental groups to suggest any motor coordination deficits in all the three periods of $\mathrm{CO}$ exposure (Fig. 3).

Blood Carboxy-Haemoglobin: There was significant $(\mathrm{P}=0.0001)$ increase in the percentage $\mathrm{COHb}$ of the experimental group $(2.06 \pm 0.12)$ when compared to the control $(0.78 \pm 0.089)$ group (Table 1.0). 


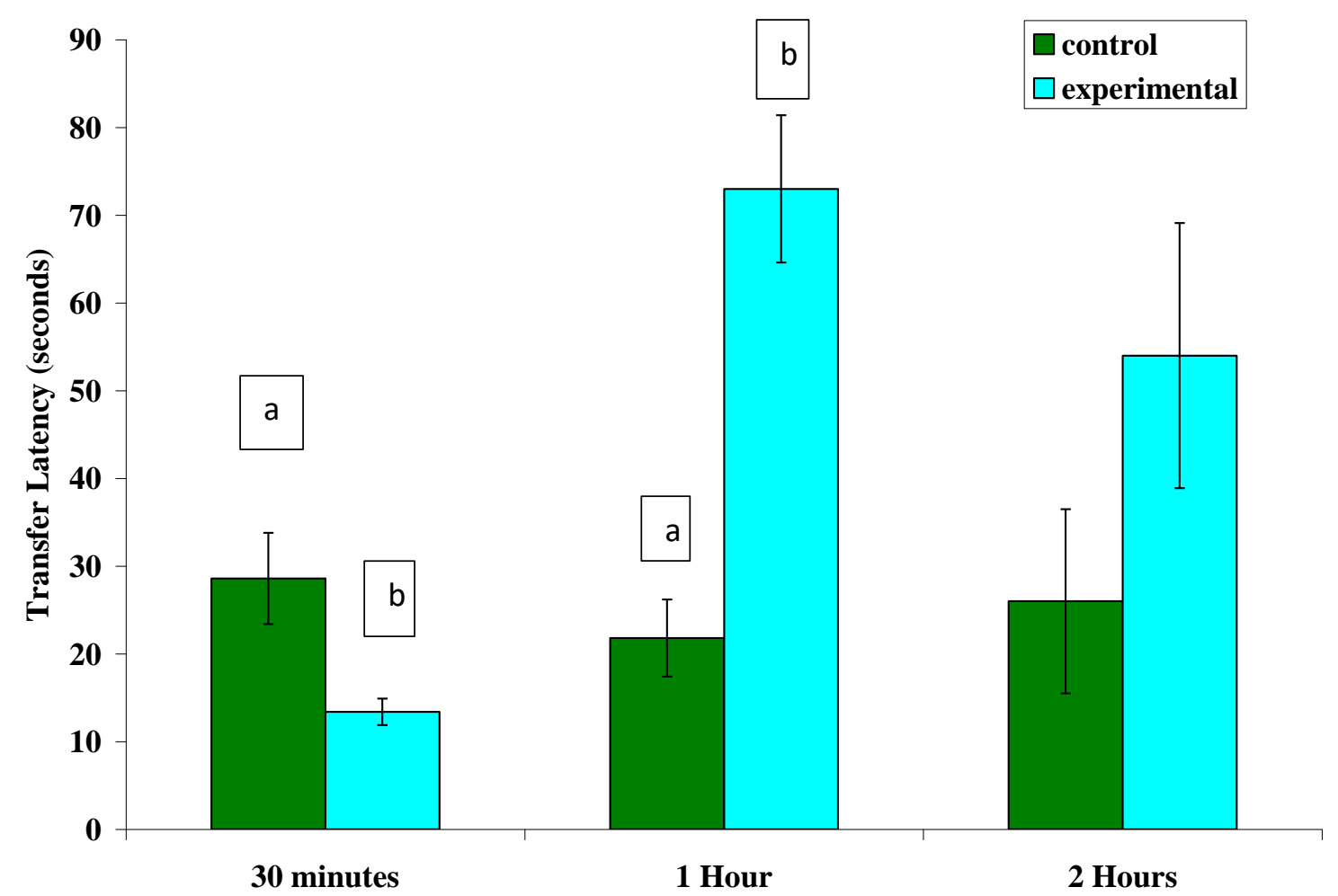

Figure 1: Transfer latencies of the control and experimental groups during the acquisition/learning test $\mathrm{a}, \mathrm{b}=$ values with different superscript letters indicate significance at $\mathrm{P}<0.05$ and its absence imply insignificance. $\mathrm{n}=6$

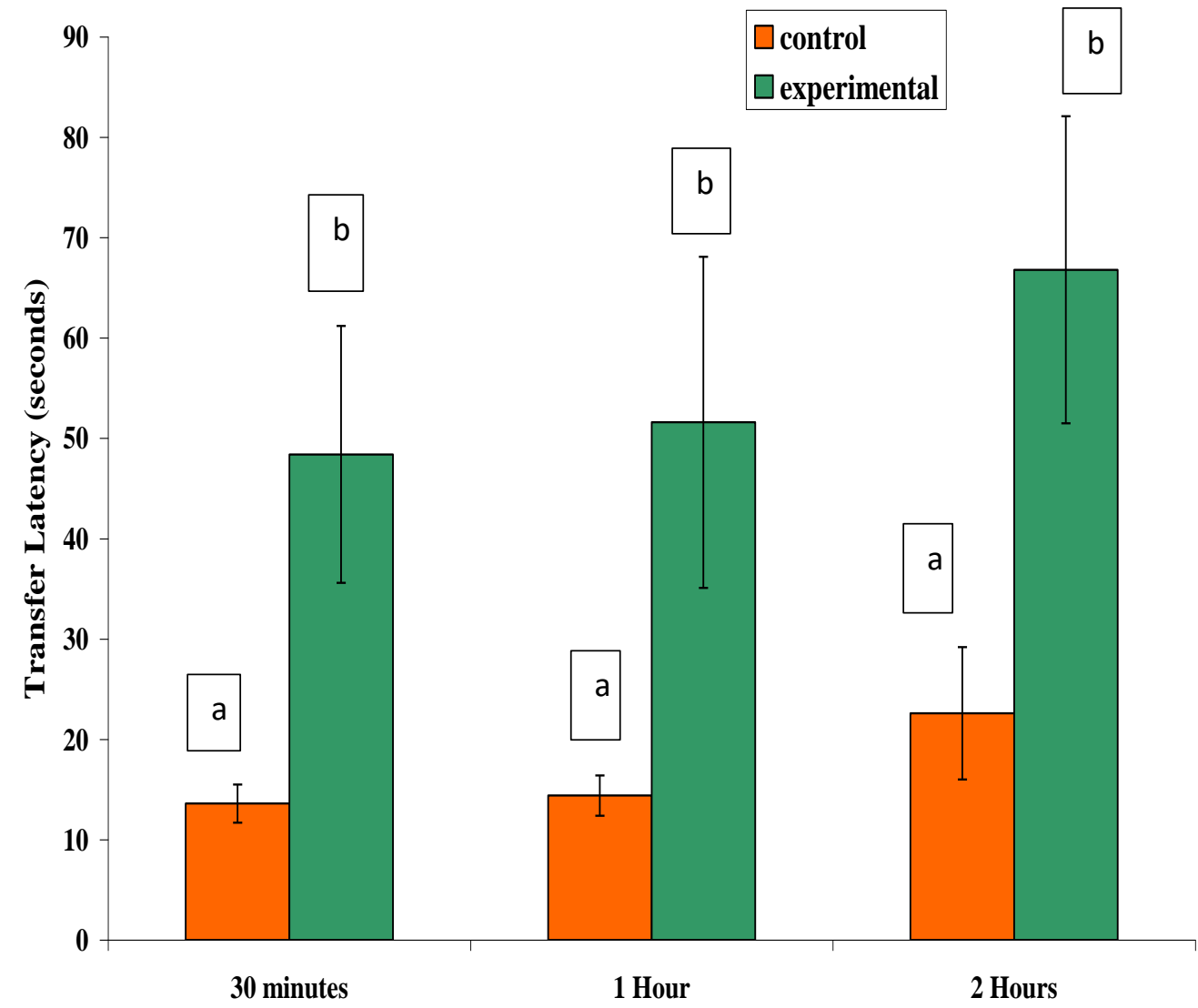

Figure 2: Transfer latencies of the control and experimental groups during the recall/memory task (Day-2). $\mathrm{a}, \mathrm{b}=$ values with different superscript letters indicate significance at $\mathrm{P}<0.05$ and its absence imply insignificance. $n=6$ 


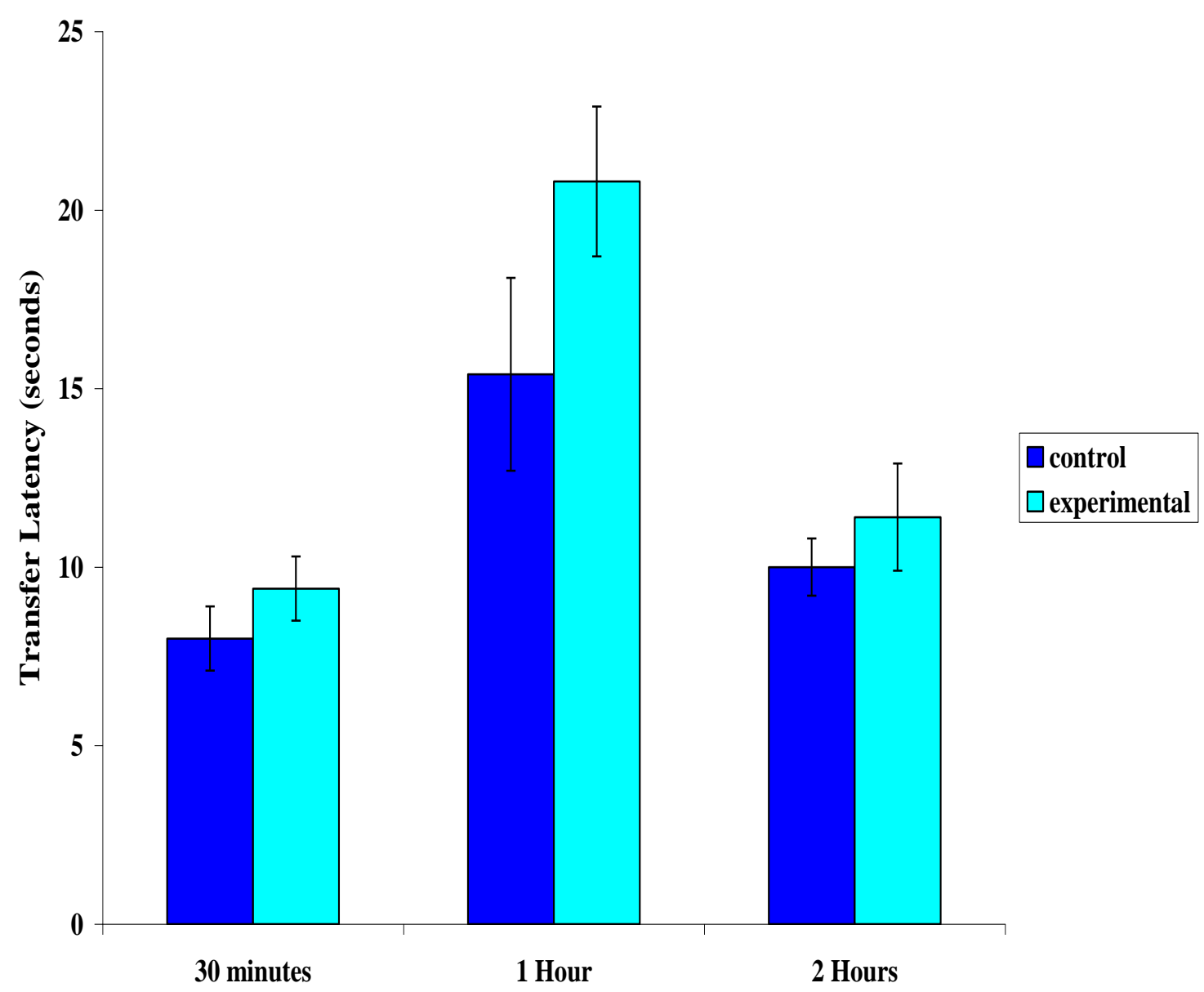

Figure 3: Latencies of the control and experimental groups during beam walk performance test.

Table 1: Percentage Carboxy-Hemoglobin in the control and experimental groups.

\begin{tabular}{ll}
\hline Groups & Percentage COHb in blood (Mean \pm SEM) \\
\hline Control & $0.76 \pm 0.089$ \\
Experimental & $2.06 \pm 0.012$ \\
\hline
\end{tabular}

\section{DISCUSSION}

Several studies in humans confirm neurotoxicity to be the most prominent symptoms in $\mathrm{CO}$ poisoning (Samuel and Micha, 2007; USEPA, 2011). Animal studies also suggest foetal susceptibility and the developing brain having the highest sensitivity among all other organs (Longo et al., 1967). Significant increase in the TLs observed in the study suggest that $\mathrm{CO}$ exposure might have affected either the acquisition of the new behaviour, recall of the new behaviour or both. While significant decrease in the TLs may suggest that CO enhanced learning and or memory. Our findings revealed enhanced ability of mice to learn the new behaviour during the 30 minutes partial exposure to $\mathrm{CO}$. This finding agrees with that of Boeihning et al., (2003) who reported that CO, together with $\mathrm{NO}$ act as gaseous neurotransmitters in the Central Nervous System (CNS) at physiological concentrations (Boeihning et al., 2003), As the exposure increases, poisoning may occur (Mannaioni et al., 2006). Karim et al., (2001) had earlier established the role played by CO produced in the body as a retrograde synaptic messenger with a prominent position in the long-term potentiation (LTP) of certain areas of the brain. In a similar study CO produce long-term 
enhancement when paired with low-frequency stimulation and results were found to be consistent with the hypothesis that $\mathrm{NO}$ and $\mathrm{CO}$, either alone or in combination, serve as retrograde messengers that produce activity-dependent presynaptic enhancement during LTP (Zhuo et al., 1993; Hawkins et al., 1994).

Previous studies reported specific toxicity of $\mathrm{CO}$ on memory functions in animals and also delayed neuronal death in areas involved in memory process (Piantadosi et al., 1997; Nabeshima et al., 1991). Equally Katoh et al., (1991) reported a 17\% decrease in pyramidal cells in the CA1 region of mice, who received pure CO compared to normal controls. Our findings were in line with the above thus, suggesting significant deterioration in learning/ acquisition after 1 hour of partial CO exposure. Mereu et al., (2000) associated the learning and memory deficits produced in rat offspring by a prenatal exposure model simulating the $\mathrm{CO}$ exposure observed in human cigarette smokers $(150 \mathrm{ppm})$ with the functional changes observed at CA3-CA1 synapses in the hippocampus. Though 30 minutes of partial CO exposure enhanced the learning process, the same period of exposure produced significant deterioration in recall after 24 hours. It can therefore be deduced that $\mathrm{CO}$ exposure may impair recall in mice. Similarly, CO poisoned subjects were found to have impaired ability to remember new temporal, linguistic, and spatial information while previous knowledge was intact (Hopkins et al., 1993). Short-term memory loss, lack of spontaneous movements and infarctions in bilateral hippocampi, temporal poles, occipital cortex, globus pallidus, cerebellum, and brainstem were apparent in an elderly man after deliberate $\mathrm{CO}$ poisoning. Although he was ambulatory six months later with normal communication; he suffered residual anterograde amnesia (Gottfried and Anjan, 2001). A case of delayed encephalopathy and cognitive sequelae were observed 4 weeks after acute $\mathrm{CO}$ poisoning, following which the patient regained some improved memory and other cognitive function after 4 weeks of treatment, including hyperbaric oxygen therapy (HBOT) (Tapeantong and Poungvarin, 2009). A significant deterioration of memory that was directly proportional to the duration of $\mathrm{CO}$ exposure was also observed. From the literature, the duration of exposure has a greater impact on the magnitude of $\mathrm{CO}$ patho-physiology than what is predicted based on the concentration of CO that was inspired (Fein et al., 1980; Penney et al., 2008).

Marginal increases in the TLs of the experimental groups in the Beam walk test, may suggest absence of any gross motor coordination deficits in all the three periods of $\mathrm{CO}$ exposure. However, previous studies have shown that gross affectation of movement is possible only at higher $\mathrm{COHb}$ level beyond $2 \%$. Headaches, generalized weakness, fatigue and sleepiness were part of the vague symptomatology observed in human subjects with $\mathrm{COHb}$ levels below $20 \%$ (Hampson et al., 2008).

The amount of Haemoglobin $(\mathrm{Hb})$ found in the blood samples were adequate $(14 \mathrm{~g} / \mathrm{dl})$, and comparable in both groups. Therefore, difference in the percentage $\mathrm{COHb}$ found in the two groups cannot be attributed to the $\mathrm{Hb}$ content. Mean $\mathrm{COHb}$ level estimated was found to be higher in the exposed group than the control. Only a small amount of $\mathrm{CO}$ is formed in the body from endogenous production, larger percentage of the gas was from exogenous sources. The level of $\mathrm{COHb}$ found in the control group was comparable to that of endogenous production; however, that of experimental group was comparable to $\mathrm{CO}$ exposure of $15 \mathrm{ppm}$ deduced from the Coburn-Forster-Kane (CFK) table (Supplementary file) (Coburn, 1965). Even though the dose of CO exposure in this study was in the range of 100 - 150 ppm, lower blood $\mathrm{COHb}$ levels were recorded. This might be because the method of exposure used in the study was partial, providing some fresh air ventilation to the experimental animals. Secondly, the prolonged time interval between exposure to $\mathrm{CO}$ and 
blood collection may have also contributed to the low percentage $\mathrm{COHb}$ recorded when compared to the exposure dose.

\section{CONCLUSION}

In conclusion, $\mathrm{CO}$ at this range and period of exposure was found to adversely affect acquisition and recall but not motor coordination in mice. Our findings were in line with many previous studies, where acute $\mathrm{CO}$ exposure from fumes resulted in functional deficits in learning and memory. However, $\mathrm{CO}$ exposure at physiological level was beneficial to the learning process. Percentage $\mathrm{COHb}$ found in the exposed group was high, thus suggesting additional exogenous exposure. It is important to note that, various effects presented here might not be attributed to only $\mathrm{CO}$, since several other contents of the generator exhaust fumes might perhaps be toxic.

\section{REFERENCES}

Akinbami, J.F.K. (2001). Renewable Energy resources and Technologies in Nigeria: Present situation, future prospects and policy framework. Mitigation and Adaptation strategies for global change. Kluwer Academic Publishers, Neitherlands, 6: 155-181.

Amitai, Y., Zlotogorski, Z., Golan-Katzav, V., Wexler, A. and Gross, D. (1998). Neuropsychological impairment from acute low-level exposure to carbon monoxide. Archives of Neurology, 55: 845-8.

Ajayi, A. and Dosunmu, O. (2002). Environmental hazards of importing used vehicles into Nigeria. Proceedings of International Symposium on Environmental Pollution Control and Waste Management, Tunis (EPCOWM'2002), 521-532.

Augustine, M.K., Choi., Leo, E. and Otterbein. (2002). Antioxidant and Redox Signaling. Emerging role of carbon monoxide in physiologic and pathophysiologic states. Mary Ann Liebert, Inc. Journal, 4(2): 227-228.

Ayodele, J.T., Adekiya A.O. and Yakubu, I. (2007). Carbon Monoxide as Indoor Pollutant in Kano Metropolis. Journal of Applied Science and Environmental Management, 11(3): 27 30.

Boehning, D., Moon, C. and Sharma, S. (2003). Carbon monoxide neurotransmission activated by CK2 phosphorylation of haeme oxygenase-2. Neuron, 40: 129-37.

Campbell, M.G. (2009). Diesel exhaust fumes, an overview. Carbon monoxide headquarters report. 02 102009/1.

Coburn, R.F. (1965). Considerations of the physiological variables that determine the blood carboxyhaemoglobin concentration in man. Journal of clinical investigation, 44: 18991910.

Earnest, B. and Carol, W. (1984). Simplified Determination of Carboxyhaemoglobin. Clinical Chemistry, 30(6): 871-874.

Fein, A., Grossman, R.F., Jones, J.G., Hoeffel, J. and McKay, D. (1980). Carbon monoxide effect on alveolar epithelial permeability. Chest, 78: 726-731.

Gottfried, J.A. and Anjan Chatterjee. (2001). Carbon monoxide-mediated hippocampal injury. Neurology, 57(1): 17.

Hampson, N.B. (1996). Carbon monoxide poisoning at an indoor ice arena and bingo hallseattle. Mobidity and Mortality Weekly Report, 45: 65-267.

Hampson, N.B. and Hauff, N.M. (2008). Carboxyhaemoglobin levels in carbon monoxide poisoning: do they correlate with the clinical picture? American Journal of Emergency Medicine, 26(6): 665-669.

Hopkins, R.O., Weaver, L.K. and Kesner, R.P. (1993). Longterm memory impairments and Hippocampal magnetic resonance imaging in carbon monoxide poisoned subjects. 
The undersea and hyperbaric medical society, Inc. Annual Scientific Meeting. World Trade and Conventional Center, Halifax, Nova Scotia, Canada.

Hawkins, R.D., Zhuo, M. and Arancio, O. (1994). Nitric oxide and carbon monoxide as possible retrograde messengers in hippocampal long-term potentiation. Journal of Neurobiology, 25(6): 652-65.

Itoh J., Nabeshima, T. and Kameyama, T. (1990). Utility of an Elevated Plus Maze for the Evaluation of memory in mice: effects of narcotropics, scopolamine and electroconvulsive shock. Psychopharmacology, 101: 27-33.

Karim, A.A., Reem, S.A., Kahkashan, M. and Yvonne, H.H. (2001). Retrograde Carbon Monoxide Is Required for Induction of Long-Term Potentiation in Rat Superior Cervical Ganglion. The Journal of Neuroscience, 21(10): 3515-3520;

Katoh, A., Nabeshima, T. and Ishimaru, H. (1991). Carbon monoxide-induced delayed amnesia, delayed neuronal death and change in acetylcholine concentration in mice. Journal of Pharmacology and Experimental Therapeutics, 256: 378-84.

Lam, S.P., Fong, .Y.Y., Kwok, A., Wong, T., Wing, Y.K. (2004). Delayed neuropsychiatric impairment after carbon monoxide poisoning from burning charcoal. Hong Kong Medical Journal, 10: 428-431.

Leon, D.P. and Rossitza, I.C. (2007). Carbon monoxide intoxication: An updated review. Journal of the Neurological Sciences, 262: 1-2, 122-130.

Longo, Lapresle J. and Fardeau M., (1967). The central Nervous system and Carbon monoxide poisoning II. Anatomical study of brain lesions following intoxication with Carbon monoxide (22 cases). In: Bour, H. and ledingham, I.M. (Ed) Carbon monoxide poisoning. Progress in Brain Research, Elsevier Vol.24, P. 31-74.

Mannaioni, P.F., Vannacci, A. and Masini, E. (2006). Carbon monoxide: the bad and the good side of the coin, from neuronal death to anti-inflammatory activity. Inflammation Research, 55: 261-73.

Mayer, H. (1999). Air pollution in cities. Atmospheric Environment, 33: 4029-4037.

Mereu, G., Cammalleri, M., Fà, M., Francesconi, W., Saba, P., Tattoli, M., Trabace, L., Vaccari, A. and Cuomo, V. (2000). Prenatal exposure to a low concentration of carbon monoxide disrupts hippocampal long-term potentiation in rat offspring. Journal of Pharmacology and Experimental Therapeutics, 294(2): 728-734.

Nabeshima, T., Katoh, A. and Ishimaru, H. (1991). Carbon monoxide-induced delayed amnesia, delayed neuronal death and change in acetylcholine concentration in mice. Journal of Pharmacology and Experimental Therapeutics, 256: 378-84.

Niel, B., Hampson, M.D., Jennette, L. and Zmaeff. (2005). Carbon monoxide poisoning from portable electric generators. American Journal of Preventive Medicine, 28(1): 123-125.

Penney, D.G. (2008) Chronic carbon monoxide poisoning: a case series. In: Penney D.G. (Ed) Carbon monoxide poisoning. Boca Raton, FL: CRC Press, U.S.A., 551-67.

Piantadosi, C.A., Zhang, J., Levin, E.D., Folz, R.J. and Schmechel, D.E. (1997). Apoptosis and delayed neuronal damage after carbon monoxide poisoning in rat. Experimental Neurology, 147: 103-14.

Ryter, S.W., Morse, D. and Choi, A.M. (2004). Carbon Monoxide: To boldly go where NO has gone before. Science's Signal Transduction Knowledge Environment, 230: RE6.

Samuel, H. and Micha, M. (2007). Prospective study of accidental carbon monoxide poisoning in 38 Swiss soldiers. Swiss Medical Journal, 135: 398-406.

Stanley, J. L., Lincoln, R. J., Brown, T. A., McDonald, L. M., Dawson, G. R., \& Reynolds, D. S. (2005). The mouse beam walking assay offers improved sensitivity over the mouse rotarod in determining motor coordination deficits induced by benzodiazepines. Journal of Psychopharmacology, 19(3), 221-227.

Sunny, O., Banjoko, Olatunde, O., Masheyi, Isaiah O., Ogunkola, Mynapelli, K.C. and Sridhar. (2008). Ambient carbon monoxide and carboxy-haemoglobin levels in 
Ibadan City, Nigeria: A source of health inequality between developed and developing nations? Journal of Environmental Health Research (JEHR), 7: 1.

Tapeantong, T. and Poungvarin, N. (2009). Delayed encephalopathy and cognitive sequelae after acute carbon monoxide poisoning: report of a case and review of the literature. Journal of the Medical Association of Thailand, 92(10): 1374-9.

United States Air Quality Guidelines (AQG). (2000). Chapter 5.5 Carbon monoxide; World Health Organization (WHO) Regional Office for Europe, Copenhagen, Denmark, Second Edition.

United States National Ambient Air Quality Standards (NAAQS). (2011). Air quality criteria for carbon monoxide: Office of Research and Development, Washington, DC: Environmental Protection Agency (EPA).

United States Environmental Protection Agency (EPA). (2011). Automobiles Emissions: An Overview. In Air and Radiation; Fact Sheet OMS- 5; 400-F-92-007.

United States Air Quality Criteria, EPA. (1991). Carbon monoxide. Washington, DC. Air Quality Criteria $(A Q C)$, Office of Research and Development. Publication no. EPA600/B-90/045F.

United States Consumer Products Safety Commission (CPSC) (2002). Incidents, deaths, and in-depth investigations associated with carbon monoxide and engine driven tools, CPSC Release No. 01-069. Available at: www.cpsc.gov/library/foia/foia03/os/weather.pdf.

World Health Organization, (2000). Chapter 5.5 Carbon monoxide; Air Quality Guidelines $(A Q G)$, Second Edition. WHO Regional Office for Europe, Copenhagen, Denmark.

Zhuo, M., Small, S.A., Kandel, E.R. and Hawkins, R.D. (1993). Nitric oxide and carbon monoxide produce activity-dependent long-term synaptic enhancement in hippocampus,260(5116):1946-1950. 